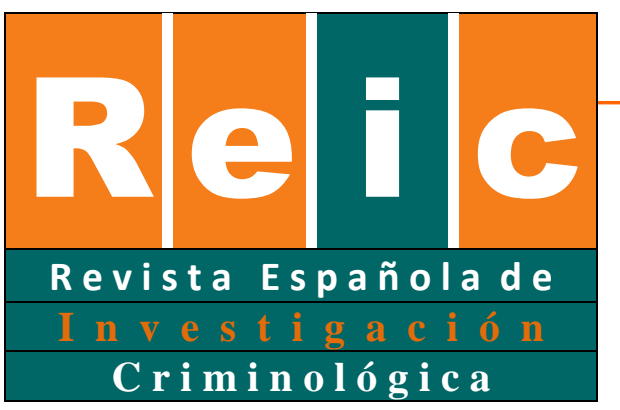

González \& Campoy

\title{
Ciberacoso y cyberbullying: diferenciación en función de los precipitadores situacionales
}

\section{Cyberharassment and cyberbullying: differences based on situational precipitators}

\author{
Abel González García ${ }^{1}$ iD \\ Universidad a Distancia de Madrid \\ Pedro Campoy Torrente \\ Universidad de Málaga
}

\section{RESUMEN}

Diferentes estudios tratan de identificar las posibles especificidades de la conducta antisocial juvenil en el ciberespacio, situando el contexto en el que se produce como eje del análisis, en el que se incluye, sobre todo, el anonimato. Asumiendo que el comportamiento no ocurre en un vacío contextual, la pregunta es si otras características del entorno pueden explicar estas conductas antisociales. Este trabajo pretende comprobar la capacidad explicativa de los precipitadores situacionales del delito (PSD) de las conductas de ciberacoso (genérico) y cyberbullying (específico), y a través de los hallazgos del presente estudio poner de manifiesto que los menores pueden sufrir dos tipos de ciberacoso, uno genérico y otro específico (cyberbullying). A partir de una muestra de 297 menores de 12 a 16 años se realizan diferentes análisis en los que los resultados obtenidos sugieren que los precipitadores son útiles para explicar estas conductas $(21 \%$ de la variablidad del ciberacoso y $39 \%$ de la variabilidad del cyberbullying). Con lo que se discute la importancia de definir adecuadamente ambos fenómenos y las limitaciones conceptuales y operativas de los precipitadores.

\footnotetext{
${ }^{1}$ La correspondencia debe dirigirse a: Abel González García. Universidad a Distancia de Madrid, Carretera de la Coruña Km. 38,500, 28400 Collado Villaba (Madrid). abel.gonzalez@udima.es
} 
Palabras clave: ciberacoso, cyberbullying, precipitadores situacionales del delito, factores de riesgo, interacción persona-ambiente.

\begin{abstract}
Various studies try to identify the potential specificities of juvenile antisocial behavior in cyberspace, placing the behavior context (anonymity) as the axis of the analysis. Assuming that behavior does not occur in a contextual vacuum, we discuss if a past from anonymity other environmental characteristics might help to explain these behaviors. This paper aims to verify the explanatory capacity of the situational precipitators of crime (SPC) in cyberharassment (generic) and cyberbullying (specific), and thus prove that minors may be subject to both, generic and specific cyber attacks. For this purpose, correlational and regression analyses were carried out on a sample of 297 children aged 12 to 16 . The results obtained suggest that precipitators are useful in explaining these antisocial behaviors (21\% of cyberharassment variability and $39 \%$ of cyberbullying variability). The importance of adequately defining both phenomena and the conceptual and operational limitations of precipitators are also discussed.
\end{abstract}

Keywords: cyberharassment, cyberbullying, situational precipitators of crime, risk factors, human-environment interaction.

\title{
1. Introducción
}

Más del 90\% de los jóvenes entre 12 y 18 años utilizan cotidianamente Internet (González, 2015), aumentando a más del 98\% de los jóvenes entre 16 y 24 años según el Instituto Nacional de Estadística, con datos referidos al año 2016 (INE, 2017). Paralelamente al avance del uso de la Tecnología de la Información y Comunicación (TIC) han ido apareciendo diferentes estudios en los que se señala un aumento "preocupante" de los casos de ciberacoso (específicamente, cyberbullying) (UNESCO, 2016).

Por lo tanto, el aumento de conductas antisociales en el ciberespacio puede ser consecuencia directa del aumento del uso de este contexto como "nuevo" lugar de relaciones (Miró, 2012), rasgo característico de la llamada generación "Millennial": personas nacidas entre 1981 y 1995 quienes desarrollan su vida cotidiana en el mundo off y online de forma integrada, siendo su ventana al mundo la pantalla de un móvil (Gutiérrez-Rubí, 2014).

En el campo de la ciencia criminológica existe una creciente necesidad de comprobar si las teorías criminológicas tradicionales son válidas para explicar también el 
comportamiento antisocial en el ciberespacio. Aparte de la aportación de evidencia científica en este sentido, también son importantes las posibles implicaciones de ello, la más interesante de las cuales es a nuestro juicio la posibilidad de que los programas de prevención deban adaptarse a las posibles diferencias que existan entre el comportamiento antisocial online y offline.

Coherentemente al avance de la investigación y en el ámbito de análisis de este estudio, ya señalaba Felson (2015) que la Criminología en particular y las ciencias sociales en general van alejándose del individuo puro como centro del universo. Ahora sabemos que los individuos responden de maneras muy distintas al cambiar sus ambientes y sus situaciones durante un día normal. Esta aseveración derivada de la investigación criminológica en el mundo físico es especialmente importante en el mundo online: ¿existen diferencias en las respuestas de los individuos cuando cambia su contexto relacional del mundo físico al virtual? Y, si así fuera, ¿son válidos los postulados tradicionales sobre la interacción personaambiente para explicar el comportamiento antisocial en el mundo online?

Así, consideramos relevantes las palabras de Agustina y Felson (2015, pp.139), quienes señalan que "los puntos de encuentro entre jóvenes se refieren a espacios, no únicamente a un lugar". Mientras el punto de encuentro en el mundo físico es a menudo la escuela (Agustina \& Felson, 2015), en el mundo online dicho punto es difuso, pero no por ello menos concreto, definiéndose en redes sociales y aplicaciones de mensajería (Bartrina, 2012; González, 2015).

Por otra parte, las conductas de acoso en el ciberespacio están siendo ampliamente estudiadas, aunque comúnmente siguen confundiéndose los conceptos de ciberacoso en general y el de cyberbullying, como variante específica. Debido a esta confusión, en este análisis, consideramos "ciberacoso genérico" como aquel formado por conductas de acoso que se realizan en el ciberespacio contra cualquier persona, conocida o no; como ciberacoso específico consideramos aquellas conductas específicas en función de las características del comportamiento. En este caso, el cyberbullying puede ser el mejor exponente, además de otros tipos de acoso como pudiera ser el online grooming, o ciberacoso sexual, o el sexting (González, 2015). El cyberbullying compartiría además los componentes del bullying 
tradicional: intencionalidad de dañar a la víctima, repetición temporal y existencia de asimetría de poder (Olweus, 1993; Patchin \& Hinduja, 2006).

Un rasgo contextual intrínseco del cyberbulluing es que se puede realizar en cualquier momento, aun estando circunscrito al ámbito escolar. Además, otra característica esencial es que debe incluir a conocidos de este círculo educativo, aunque la víctima no tenga por qué conocer la identidad concreta de sus agresores (Patchin \& Hinduja, 2006). Por ello, una de las teorías explicativas aplicadas al ciberacoso general es la teoría de las actividades cotidianas de Cohen y Felson (1979), adaptada por Miró (2012), en la que el acoso resulta de la confluencia en el ciberespacio de un agresor motivado, una víctima vulnerable y una ausencia de guardianes capaces. Huelga señalar que esta es una teoría que pudiera aplicarse a casi cualquier delito cometido en el ámbito de la TIC. Por ello, centrándonos en el ámbito específico del cyberbullying, consideramos tres de las teorías clásicas más frecuentemente aplicadas a este ámbito.

En primer lugar, la Teoría de la Tensión (Agnew, 1992), aplicada al ciberespacio por Jang, Song y Kim (2014), y Patchin e Hinduja (2011). Postula que las personas cometen conductas antisociales porque están sometidas a diversas fuentes de tensión; en el caso del cyberbullying, puede ser una victimización previa, experimentando así los agresores una emoción negativa que lleva a la descarga de la tensión mediante la agresión.

En segundo lugar, la Teoría Social Cognitiva (Bandura, 1999) ha sido aplicada al cyberbullying por Lazuras, Barkoukis, Ourda y Txorbatzoudis (2013), y por Pornari y Wood (2010); los mecanismos de desvinculación moral (justificación moral, difusión de la responsabilidad, desplazamiento de la responsabilidad, comparación ventajosa, atribución de la responsabilidad o distorsión de las consecuencias) son predictores de la conducta de cyberbullying, debido a la configuración del ciberespacio. Entre todos los mecanismos destacan la creencia de lo que sucede en Internet no es importante (difusión de la responsabilidad) y el pensamiento de que lo que les sucede a las víctimas no es grave (distorsión de las consecuencias).

En tercer lugar, la teoría de la Acción Razonada de Ajzen (2012), aplicada al cyberbullying por Doane, Pearson y Kelley (2014) y por Heirman y Walrave (2012), indica que la disponibilidad de medios electrónicos, la percepción de control y el anonimato 
facilitan las intenciones de querer agredir a alguien, sumándose a ello las actitudes positivas hacia el cyberbullying y la percepción de que no se hace nada malo. Todo ello predispondría para la agresión online porque influiría en las normas subjetivas que interioriza el sujeto.

A efectos de este trabajo, más allá de la mera enumeración de las condiciones contextuales en las que se produce la conducta, interesa conocer por qué se produce el comportamiento de acoso a partir de la interacción persona-ambiente. Para ello se ha considerado necesario abordar esta interacción a partir de los precipitadores situacionales en el ciberespacio (PSD), aplicándolos al análisis de las conductas de ciberacoso general y cyberbullying. Nuestra pretensión es conocer qué capacidad explicativa tiene esta vertiente teórica y averiguar si existen diferencias significativas a la hora de explicar ambas conductas.

Partimos del trabajo de González (2015), en el que los PSD se revelaron como una variable predictora del cyberbullying, junto con la alta impulsividad. Ambas variables explicaron un $30 \%$ de la variabilidad total, consiguiendo clasificar correctamente sendas variables el $97.4 \%$ de los casos observados.

\section{Magnitudes empíricas}

Debemos realizar una prevención con respecto a la magnitud empírica de los fenómenos aquí estudiados: las cifras de ciberacoso genérico, con carácter general en la literatura, no se han estudiado de forma diferenciada a otras formas de acoso específico. Una de las principales razones esgrimidas para explicar este hecho es la asimilación de este concepto al de cyberbullying, como señalamos anteriormente (González, 2015). Partiendo de esta idea, mostraremos los principales trabajos que han tratado de medir los fenómenos que se analizan en el presente estudio.

Para el caso del cyberbullying, uno de los principales estudios que ha mostrado la prevalencia de este fenómeno internacionalmente es el de Patchin e Hinduja (2012); su revisión de 44 trabajos sitúa la tasa de victimización entre un 5.5\% y un 58\% (oscilando entre un $4 \%$ y un $44.1 \%$ para los agresores). Las diferencias porcentuales podrían deberse a dos cuestiones (González, 2015): bien a que los diferentes estudios miden fenómenos diferentes, bien a que en el caso del cyberbullying se manejen diferentes definiciones (más o menos 
amplias) sobre las conductas incluidas. Y este es el motivo por el que se tratará de conocer si estamos ante dos fenómenos diferentes, por un lado, el ciberacoso genérico, y por otro, como una parte del primero, el cyberbullying.

Si nos centramos en España existen también cifras dispares: uno de los primeros estudios rigurosos sobre el fenómeno es el del Defensor del Pueblo (2007), que sitúa en un $5.5 \%$ el porcentaje de estudiantes que había llevado a cabo estas conductas; por otro lado, el Observatorio Estatal de Convivencia Escolar (2008) obtiene unos porcentajes de entre un $2.5 \%$ y un 3.5\%; además, Avilés (2009) reporta entre un 3\% y un 4.4\% de agresores; MoraMerchán, Ortega, Calmaestra y Smith (2010) refieren un 7.4\% de agresores, mientras que el estudio del Instituto Nacional de Tecnologías de la Información (INTECO; 2010) habla de un 5\% de agresores. Estos datos contrastan con los ofrecidos por Garaigordobil y Aliri (2013), quienes reportan entre un 7.8\% y un 7.7\% (para hombres y mujeres); González (2015) halla un $5.1 \%$ de agresores que haya cometido estas conductas más de una vez en el último año. Recientemente, Romera, Cano, García-Fernández y Ortega (2016) ofrecen un porcentaje de un $5.5 \%$ de agresores. En síntesis los porcentajes señalan que entre un $2.5 \%$ y un $7.8 \%$ de los jóvenes serían ciberacosadores.

En términos de victimización las cifras varían al alza, en ocasiones, de manera acusada: el Observatorio Estatal de Convivencia Escolar (2008) obtiene una tasa de entre un 2.5\% y un 7\%; Avilés (2009) la sitúa entre un 4.5\% y un 4.7\%; Buelga, Cava y Musitu (2010) refieren entre un 24.6\% y un 29\%; INTECO (2010) informan de un 8\%; Mora-Merchán et al. (2010) reportan un 10.8\%; Miró y García (2014) hallan un 53.7\% de victimización (de cualquier tipo, no sólo ciberacoso); Garaigordobil y Aliri (2013) ofrecen entre un 12.5\% y un 17.6\% de victimización (hombres y mujeres); González (2015) reporta un 10.3\% de jóvenes víctimas y Romera et al. (2016) un 9.3\%.

Como se ha tratado de exponer, encontramos cifras muy dispares entre las mediciones de la agresión y de la victimización, lo que quizá podría deberse a que se están midiendo fenómenos diferentes, o bien que se confunde el ciberacoso genérico con el ciberacoso específico de cyberbullying. 


\section{Precipitadores situacionales del delito}

Nuestro marco teórico procede de la perspectiva de los precipitadores situacionales del delito, que se ocupa del "cómo" interactúa la persona con su entorno inmediato y de cómo éste puede influir en el proceso de decisiones del sujeto para que la conducta antisocial se produzca (Campoy \& Summers, 2015; Wortley, 2008). Hasta la fecha, este análisis se ha hecho primordialmente en el mundo offline, con algunas excepciones. Algunos ejemplos en diferentes ámbitos pueden encontrarse en Cockbain y Wortley (2015), en el que se explora el tráfico de niños en el Reino Unido; en Homel, Macintyre y Wortley (2014), quienes estudian el proceso de toma de decisiones de los ladrones de viviendas; o en Thompson y Leclerc (2014) sobre el fenómeno del acoso desde el punto de vista de los PSD.

Habiendo acuerdo a la hora de considerar el ciberespacio como un "nuevo ámbito de oportunidad criminal” (Miró, 2011, pp.3), en el que se dan comportamientos delictivos en “otro lugar" distinto al medio físico (Miró, 2012, pp.28-29), su uso como factores explicativos parece adecuado.

Aunque es necesario señalar que los PSD son conceptos complicados a la hora de ser operativizados, debido fundamentalmente a la "ingente cantidad de perspectivas teóricas que los sustentan" (Campoy \& Summers, 2015), existe un cuerpo creciente de literatura sobre la aplicación de las técnicas de prevención situacional en el ciberespacio (a modo de ejemplo, Basamanowicz \& Bouchard, 2011; Maimon, Alper, Sobesto, \& Cukier, 2014; Reyns, 2010, o; Stockman, 2014). Considerando los PSD como parte fundamental de las 25 técnicas de prevención situacional (Campoy \& Summers, 2015), no parece descabellado realizar un estudio vinculando los PSD y el comportamiento antisocial de los jóvenes en el ciberespacio.

Así, los tipos de precipitadores en el espacio propuestos por Wortley (2008) se concretan en cuatro grupos de PSD, dentro de los cuales existen cuatro tipologías concretas (con un total de dieciséis PSD). Enumeramos brevemente estas tipologías (para una revisión, véase Campoy y Summers, 2015):

- Detonantes: Hacen referencia a la activación de pensamientos y/o sentimientos que impulsan a las personas a llevar a cabo un comportamiento después de recibir un estímulo del ambiente inmediato en el que se halla. En este grupo encontramos desencadenantes, 
señales, imitación y expectativas. Los desencadenantes se refieren a un estímulo ambiental que provoca una respuesta involuntaria, pero predecible (Wortley, 1998); las señales se relacionan con los elementos del ambiente que nos ofrecen información sobre el comportamiento que se espera de nosotros en un momento determinado. La excitación producida al observar imágenes con contenido sexual o bien al cruzar una calle tras ponerse el semáforo en verde son ejemplos, respectivamente, de una y otra categoría de PSD. La imitación (la emulación de una conducta observada) (Bandura, Ross, \& Ross, 1963), y las expectativas (cómo responde una persona a partir de sus ideas preconcebidas sobre una situación determinada) cierran el grupo de detonantes.

- Presiones: El grupo de presiones está configurado por el conformismo, la obediencia, la conformidad (o desafío) y el anonimato. Estos PSD engloban las situaciones en las que un individuo lleva a cabo comportamientos influenciados por la presión de su grupo social inmediato. La tendencia de las personas a asumir las normas comportamentales, incluso cuando éstas son abiertamente antisociales, es la característica principal del conformismo. La obediencia se refiere al cumplimiento de órdenes de terceras personas que están legitimadas por el resto del grupo. La conformidad (o desafío, su opuesto) viene a definirse como un proceso mediante el cual se atiende a peticiones de otras personas, aunque para ello sea necesario llevar a cabo conductas antisociales. Por último, el anonimato engloba los comportamientos que se producen como fruto de la desinhibición percibida por las personas cuando actúan dentro de un conjunto amplio de individuos.

- Permisos: El grupo de permisos se compone por cuatro tipos de minimizaciones: de las reglas, de la (propia) responsabilidad, de las víctimas o de las consecuencias (de los actos). Estas minimizaciones distorsionan el proceso de razonamiento de la persona y le permiten llevar a cabo conductas antisociales. Auto-justificarse aludiendo a una supuesta normalidad (todos lo hacen) es el componente principal de la minimización de la regla; la minimización de la responsabilidad se refiere a culpar a factores externos por nuestro comportamiento; la minimización de la víctima alude a la creencia de que actuar contra una persona o colectivo no es grave, según sus propios prejuicios. Por último, la minimización de las consecuencias se produce al negar el daño producido por el propio comportamiento, creyendo que éste es asumido sin coste por las víctimas.

Revista Española de Investigación Criminológica

Artículo 4, Número 16 (2018)

www.criminologia.net

ISSN: 1696-9219 
- Provocaciones: El grupo de provocaciones engloba aquellas situaciones en las que el individuo lleva a cabo comportamientos antisociales afectado por el estrés de la situación. Engloba la frustración (estado emocional de una persona a la que no se le permite el acceso a un objetivo), el hacinamiento (estado inducido por la alta concentración de personas alrededor del sujeto), la territorialidad (reclamación, percibida como legítima, de una entidad -propiedad o espacio-, que puede ser defendida mediante conductas antisociales) y los estresores ambientales (agentes externos procedentes de la naturaleza que afectan a las decisiones de las personas, como la temperatura o la lluvia, por ejemplo).

Para finalizar esta explicación, mostraremos algunos estudios que han profundizado en alguno de estos constructos en el ámbito ciberespacial. Por ejemplo, Hinduja (2008) estudió el anonimato en la "piratería musical”, así como Baggili y Rogers (2009) en el ámbito de la ciberdelincuencia auto-informada y Ševčíková y Šmahel (2009) en relación a conductas de ciberacoso.

Pornari y Wood (2010) han estudiado la minimización de las reglas en conductas de ciberagresión entre iguales, además de componentes relacionados con la minimización de la responsabilidad vinculada al anonimato. Hinduja e Ingram (2008) incorporan la minimización de las reglas en su estudio sobre "piratería musical". La minimización de la víctima, entre otros componentes, ha sido estudiada por Sticca, Ruggieri, Alsaker y Perren (2013). Akbulut et al. (2008) enfocan su trabajo sobre conductas académicas deshonestas desde el punto de vista del conformismo.

\section{PSD y ciberespacio: conductas de acoso genérico y específico}

A continuación, presentamos los objetivos y la metodología empleada en el presente estudio, así como los análisis seguidos para conocer la influencia de los PSD en las conductas de acoso general y específico (cyberbullying).

\subsection{Objetivo e hipótesis}

El objetivo principal de esta investigación es conocer el poder predictivo de los precipitadores a la hora de llevar a cabo conductas de ciberacoso general y cyberbullying también. Se 
plantea un objetivo secundario, que es comprobar que los menores en el ciberespacio sufren dos tipos de ciberacoso: uno genérico y otro específico (caracterizado como cyberbullying). Se plantean las siguientes hipótesis:

- $\quad \mathrm{H}_{1}=$ Los PSD son capaces de explicar un porcentaje elevado de la variabilidad de las conductas de ciberacoso (genérico y específico).

- $\mathrm{H}_{2}=$ Los PSD con mayor poder predictivo son los más frecuentes en el grupo de agresores.

- $\mathrm{H}_{3}=\mathrm{La}$ interacción de los PSD es diferente en el ciberacoso genérico y en el específico.

\subsection{Método}

\subsubsection{Datos}

Los datos empleados son los recogidos por González (2015, pp.119-132), a partir de un cuestionario diseñado ad hoc que se auto-administró bajo supervisión del equipo investigador. Partimos de una muestra de 297 estudiantes de secundaria de la zona noroeste de la Comunidad de Madrid, sobre un total de 16 centros públicos y 1440 estudiantes de primer a cuarto curso de la ESO (Error muestral $= \pm 5.65 \%$ ). La muestra se distribuye en un $51.5 \%$ de chicos y un $48.5 \%$ de chicas, siendo la edad media de los mismos de 14,42 años (Desviación típica=1.52).

\subsubsection{Procedimiento}

En primer lugar, la variable dependiente "ciberacoso genérico" se construyó a partir de la frecuencia de doce conductas (Tabla 1).

\section{Tabla 1.}

Conductas incluidas en "ciberacoso genérico"

\begin{tabular}{|l|l|}
\hline \multirow{2}{*}{ Ciberacoso (general) } & Envío de amenazas/insultos (correo electrónico) \\
\cline { 2 - 2 } & Envío de amenazas/insultos (teléfono móvil) \\
\hline
\end{tabular}




\begin{tabular}{|l|l|}
\hline & Envío de imágenes humillantes de terceros \\
\cline { 2 - 2 } & Difusión online de bromas pesadas, rumores, cotilleos \\
\cline { 2 - 2 } & Difusión de link de las bromas pesadas, rumores, cotilleos \\
\cline { 2 - 2 } & Usurpación de identidad \\
\cline { 2 - 2 } & Grabar una humillación a otra persona (móvil) \\
\cline { 2 - 2 } & Enviar las imágenes humillantes grabadas \\
\hline & Grabar una agresión a otra persona \\
\hline & Difundir el vídeo o imágenes de una agresión \\
\hline Excluir deliberadamente (online) a otra persona \\
\hline & Difundir secretos online de terceros \\
\hline
\end{tabular}

A partir de las respuestas se crearon dos grupos: el de ciberacosadores (quienes respondieron de manera positiva a la realización de, al menos, una conducta de ciberacoso en los últimos 12 meses) y el de personas no involucradas en estas conductas. El grupo de ciberacosadores supone el $43.2 \%$ de la muestra $(\mathrm{N}=118)$.

El cyberbullying se construyó a partir de ocho conductas (Tabla 2). Este grupo engloba un $26.7 \%$ de la muestra $(\mathrm{N}=60)$.

\section{Tabla 2.}

Conductas de cyberbullying

\begin{tabular}{|l|l|}
\hline \multirow{4}{*}{$\begin{array}{c}\text { Ciberacoso específico } \\
\text { (cyberbullying) }\end{array}$} & Envío de comentarios injuriosos de compañeros/as \\
\cline { 2 - 2 } & Envío de imágenes humillantes de compañeros/as \\
\cline { 2 - 2 } & Subir a la red un vídeo humillante de un compañero/a \\
\cline { 2 - 2 } & Creación de web/perfil falso de un compañero/a \\
\cline { 2 - 2 } & Difundir rumores falsos de compañeros/as \\
\hline & Envío de amenazas a un compañero/a por el móvil \\
\cline { 2 - 2 } & Envío de amenazas online \\
\cline { 2 - 2 } & Usurpar la identidad de un compañero/a \\
\hline
\end{tabular}

Para construir las variables independientes, de entre los dieciséis PSD se operativizaron quince, mediante narrativas "dirigidas”, orientándolas a supuestos concretos para conocer las razones por las que los jóvenes declaran realizar conductas de ciberacoso y cyberbullying. Las narrativas utilizadas se presentan en la tabla 3. Para comprobar la consistencia del clúster, se realizaron pruebas de fiabilidad, con un resultado de .77 (Alfa de Cronbach), asumiéndose que es aceptable al ser superior a .70 (Cortina, 1993). Además, se decidió prescindir de los 
estresores ambientales, dado que los múltiples contextos en los que se desarrolla la conexión a internet nos impiden controlar esta variable.

\section{Tabla 3.}

Narrativas utilizadas. "Lo hago porque..."

\begin{tabular}{|l|l|}
\hline \multicolumn{1}{|c|}{ Narrativa } & \multicolumn{1}{c|}{ Tipo de precipitador } \\
\hline $1 \ldots$ respondo rápidamente a una agresión & Desencadenante \\
\hline $2 \ldots$ la otra persona se lo merece & Señales \\
\hline $3 \ldots$ mi familia o amigos también lo hacen y lo imito & Imitación \\
\hline $4 \ldots$ es lo normal en Internet & Expectativas \\
\hline $5 \ldots$ es normal en mi grupo de amigos & Conformidad \\
\hline $6 \ldots$ alguien me dice que lo haga y lo hago & Obediencia \\
\hline $7 \ldots$ es algo que hay que hacer. Es un reto & Desafío \\
\hline $8 \ldots$ es muy raro que me pillen & Anonimato \\
\hline $9 \ldots$ aunque esté prohibido lo hago & Minimizar la regla \\
\hline $10 \ldots$ en internet todo está permitido & Minimizar la responsabilidad \\
\hline $11 \ldots$ no me pasará nada, aunque me pillen & Minimizar las consecuencias \\
\hline $12 \ldots$ a las personas a las que lo hago nos les pasará nada grave & Minimizar a la víctima \\
\hline $13 \ldots$ me siento frustrado & Frustración \\
\hline $14 \ldots$ estoy rodeado de muchas personas & Hacinamiento \\
\hline $15 \ldots$ necesito defender mi imagen y la de mis amigos en Internet & Territorialidad \\
\hline
\end{tabular}

\subsubsection{Análisis de datos}

Se dicotomizaron las variables dependientes para obtener un grupo de agresores (quienes han cometido una o más veces alguna de las doce conductas planteadas -ciberacoso general- y alguna de las 8 que se corresponden con el cyberbullying). Así, 1=No ciberacosador y 2=Ciberacosador. Para las variables independientes se asignó un rango de 1 a 4 (1=Nunca, hasta $4=$ Siempre o casi siempre).

Se realizaron dos análisis de regresión logística binaria (uno por conducta). Se tomó esta decisión porque consideramos que facilita realizar un pronóstico probabilístico sobre la ocurrencia o no del evento (ciberacoso y cyberbullying) entre los sujetos de un grupo (acosadores). El método empleado es el de selección por pasos sucesivos, en función de la probabilidad del estadístico de Wald (Pardo-Merino \& Ruiz-Díaz, 2002). 


\subsection{Resultados}

\subsubsection{Incidencia de las conductas de ciberacoso y cyberbullying}

En primer lugar, se ofrece la incidencia de las conductas de ciberacoso genérico (Tabla 4) y de cyberbullying (Tabla 5). Todos estos datos se adaptan de la investigación previa de González (2015), que suponen la base del presente estudio, como ya se ha especificado en el apartado de metodología.

De las doce conductas establecidas se halló que la más frecuente es "difundir bromas pesadas, rumores o cotilleos", seguida del "envío del link" de dichas bromas. "Excluir deliberadamente a alguien online" y "difundir secretos de terceras personas" son el resto de conductas más habituales.

\section{Tabla 4.}

Incidencia del ciberacoso (\%)

\begin{tabular}{|l|c|c|c|c|c|}
\hline \multicolumn{1}{|c|}{ Conducta } & (N) & Nunca & $\begin{array}{c}\text { Una o dos } \\
\text { veces }\end{array}$ & $\begin{array}{c}\text { A } \\
\text { menudo }\end{array}$ & $\begin{array}{c}\text { Siempre/ Casi } \\
\text { siempre }\end{array}$ \\
\hline $\begin{array}{l}\text { Envío de amenazas o insultos (correo } \\
\text { electrónico) }\end{array}$ & 286 & 93.4 & 4.9 & 0.3 & 1.4 \\
\hline $\begin{array}{l}\text { Envío de amenazas o insultos } \\
\text { (teléfono móvil) }\end{array}$ & 286 & 90.2 & 7.3 & 1.4 & 1 \\
\hline $\begin{array}{l}\text { Envío de imágenes humillantes de } \\
\text { terceros }\end{array}$ & 286 & 91.6 & 7 & 0.7 & 0.7 \\
\hline $\begin{array}{l}\text { Envío del link de imágenes } \\
\text { humillantes de otras personas }\end{array}$ & 284 & 90.8 & 6.3 & 1.8 & 1.1 \\
\hline $\begin{array}{l}\text { Difusión de bromas pesada, rumores, } \\
\text { cotilleos }\end{array}$ & 284 & 76.1 & 18.7 & 3.2 & 2.1 \\
\hline $\begin{array}{l}\text { Envío del link de bromas pesadas, } \\
\text { rumores, cotilleos }\end{array}$ & 285 & 86 & 11.9 & 1.1 & 1.1 \\
\hline Usurpación de identidad & 283 & 92.2 & 6.7 & 0.4 & 0.7 \\
\hline Grabar una humillación con el móvil & 285 & 94.7 & 3.5 & 1.1 & 0.7 \\
\hline $\begin{array}{l}\text { Enviar imágenes humillantes } \\
\text { grabadas }\end{array}$ & 285 & 95.1 & 3.5 & 1.4 & 0 \\
\hline Grabar una agresión & 282 & 97.2 & 1.4 & 0.4 & 1.1 \\
\hline $\begin{array}{l}\text { Envío del vídeo o imágenes de una } \\
\text { agresión }\end{array}$ & 284 & 97.5 & 0.7 & 0.7 & 1.1 \\
\hline Difundir secretos & 285 & 87.4 & 9.8 & 1.4 & 1.4 \\
\hline
\end{tabular}


Excluir deliberadamente a alguien online

283

86.2

10.2

1.8

1.8

Fuente: A partir de González (2015, pp.137)

En el caso del cyberbullying, las conductas más frecuentes son "envío a otras personas de comentarios injuriosos de compañeros/as", seguidas del "envío de imágenes humillantes". La conducta con menor incidencia es "subir vídeos humillantes de compañeros a la red" (Tabla 5).

Tabla 5.

Incidencia del cyberbullying (\%)

\begin{tabular}{|l|l|l|c|c|c|}
\hline \multicolumn{1}{|c|}{ Conducta } & $(\mathbf{N})$ & Nunca & $\begin{array}{c}\text { Una o dos } \\
\text { veces }\end{array}$ & $\begin{array}{c}\text { A } \\
\text { menudo }\end{array}$ & $\begin{array}{c}\text { Siempre / Casi } \\
\text { siempre }\end{array}$ \\
\hline $\begin{array}{l}\text { Envío de comentarios injuriosos de } \\
\text { compañeros/as }\end{array}$ & 230 & 81.7 & 12.2 & 5.2 & 0.9 \\
\hline $\begin{array}{l}\text { Envío de imágenes humillantes de } \\
\text { compañeros/as }\end{array}$ & 230 & 87 & 8.7 & 3 & 1.3 \\
\hline $\begin{array}{l}\text { Subir un vídeo humillante de un } \\
\text { compañero/a }\end{array}$ & 229 & 96.1 & 1.7 & 1.7 & 0.4 \\
\hline $\begin{array}{l}\text { Creación de web/perfil falso en red } \\
\text { social de un compañero/a }\end{array}$ & 230 & 97.4 & 1.7 & 0.4 & 0.4 \\
\hline $\begin{array}{l}\text { Difundir rumores falsos de } \\
\text { compañeros/as online }\end{array}$ & 230 & 92.6 & 5.7 & 1.3 & 0.4 \\
\hline $\begin{array}{l}\text { Envío de amenazas a través del } \\
\text { teléfono móvil a un compañero/a }\end{array}$ & 230 & 95.7 & 3.9 & 0 & 0.4 \\
\hline $\begin{array}{l}\text { Envío de amenazas online a un } \\
\text { compañero/a }\end{array}$ & 226 & 93 & 4.8 & 1.7 & 0.4 \\
\hline $\begin{array}{l}\text { Usurpar la identidad y hacerse pasar } \\
\text { por un compañero/a }\end{array}$ & 226 & 93.8 & 6.2 & 0 & 0 \\
\hline
\end{tabular}

Fuente: A partir de González (2015, pp.143)

El porcentaje de agresores en ciberacoso general supone un $43.2 \%$, muy superior al del cyberbullying, del 26.7\% (Tabla 6). Para obtener este dato se han agrupado a aquellos sujetos que han cometido, al menos, una de las conductas de ciberacoso genérico alguna vez, y en el caso del cyberbullying, se ha procedido de la misma manera, arrojando las cifras en los cuatro grupos (agresores/no agresores; ciberacoso genérico/cyberbullying) que se indican a continuación. 


\section{Tabla 6.}

Proporción de agresores: acoso general y cyberbullying

\begin{tabular}{|c|c|c|}
\hline \multirow{2}{*}{ Variables } & \multicolumn{2}{|c|}{$\begin{array}{c}\text { Proporción } \\
(\%)\end{array}$} \\
\cline { 2 - 3 } & Sí & No \\
\hline Ciberacoso $(\mathrm{N}=273)$ & 43.2 & 56.8 \\
\hline Cyberbullying $(\mathrm{N}=225)$ & 26.7 & 73.3 \\
\hline
\end{tabular}

\subsubsection{Incidencia de los PSD}

La incidencia de los PSD se muestra en la Tabla 7. Las señales son el precipitador más frecuente, seguido del desencadenante $\mathrm{y}$, en tercer lugar, la territorialidad. El resto de precipitadores se sitúan en los mismos porcentajes, a excepción del desafío.

\section{Tabla 7.}

Porcentaje auto-informado de precipitadores (\%)

\begin{tabular}{|l|c|c|c|c|}
\hline \multicolumn{1}{|c|}{ Precipitador } & Nunca & A veces & A menudo & Siempre \\
\hline 1. Desencadenante & 71.8 & 20.9 & 2.3 & 5.1 \\
\hline 2. Señales & 69.7 & 19.7 & 3.9 & 6.7 \\
\hline 3. Imitación & 89.7 & 5.7 & 2.9 & 1.7 \\
\hline 4. Expectativas & 87.5 & 6.8 & 1.1 & 4.5 \\
\hline 5. Conformidad & 88.6 & 7.4 & 1.1 & 2.9 \\
\hline 6. Obediencia & 90.8 & 6.3 & 1.1 & 1.7 \\
\hline 7. Desafío & 96.6 & 1.1 & 0.6 & 1.7 \\
\hline 8. Anonimato & 92 & 5.7 & 1.1 & 1.1 \\
\hline 9. Minimizar la regla & 90.9 & 5.1 & 1.1 & 2.9 \\
\hline 10. Minimizar la responsabilidad & 86.9 & 4.6 & 4 & 4.6 \\
\hline 11. Minimizar las consecuencias & 88.6 & 4 & 1.7 & 5.7 \\
\hline 12. Minimizar a la víctima & 90.2 & 4 & 1.1 & 4.6 \\
\hline 13. Frustración & 87.9 & 6.9 & 1.1 & 4 \\
\hline 14. Hacinamiento & 87.9 & 5.8 & 2.3 & 4 \\
\hline 15. Territorialidad & 80.2 & 7 & 4.7 & 8.1 \\
\hline
\end{tabular}

Fuente: elaboración propia a partir de González (2015).

En la Tabla 8 se ofrecen los estadísticos descriptivos de las variables independientes (valor mínimo de 1 -nunca- y máximo de 4 -muchas veces-). Se puede observar que por 
encima de 1.4 solo se sitúan las señales y los desencadenantes. Entre 1.20 y 1.40 se encuentran las expectativas, minimizar la responsabilidad, minimizar las consecuencias, minimizar a la víctima, el hacinamiento y la territorialidad. Por debajo de 1.20 están el resto de precipitadores.

\section{Tabla 8.}

Estadísticos descriptivos de los PSD

\begin{tabular}{|l|c|c|c|c|c|}
\hline \multicolumn{1}{|c|}{ Precipitador } & N & Mín. & Máx. & Med. & Sd \\
\hline 1. Desencadenante & 177 & 1 & 4 & 1.41 & 0.771 \\
\hline 2. Señales & 178 & 1 & 4 & 1.48 & 0.858 \\
\hline 3. Imitación & 175 & 1 & 4 & 1.17 & 0.548 \\
\hline 4. Expectativas & 176 & 1 & 4 & 1.23 & 0.688 \\
\hline 5. Conformidad & 175 & 1 & 4 & 1.18 & 0.588 \\
\hline 6. Obediencia & 174 & 1 & 4 & 1.14 & 0.497 \\
\hline 7. Desafío & 175 & 1 & 4 & 1.07 & 0.429 \\
\hline 8. Anonimato & 175 & 1 & 4 & 1.16 & 0.575 \\
\hline 9. Minimizar la regla & 175 & 1 & 4 & 1.11 & 0.440 \\
\hline 10. Minimizar la responsabilidad & 175 & 1 & 4 & 1.26 & 0.742 \\
\hline 11. Minimizar las consecuencias & 174 & 1 & 4 & 1.20 & 0.680 \\
\hline 12. Minimizar a la víctima & 174 & 1 & 4 & 1.25 & 0.752 \\
\hline 13. Frustración & 174 & 1 & 4 & 1.15 & 0.554 \\
\hline 14. Hacinamiento & 175 & 1 & 4 & 1.21 & 0.659 \\
\hline 15. Territorialidad & 80.2 & 1 & 4 & 1.23 & 0.683 \\
\hline
\end{tabular}

\subsubsection{Correlaciones entre variables dependientes e independientes}

Se realizó un análisis de correlaciones (Tabla 9) a través de la obtención del coeficiente de Spearman. Los resultados muestran que la conducta de ciberacoso genérico correlaciona levemente con el cyberbullying, así como con el precipitador "hacinamiento". Para el cyberbullying no se encontró correlación con los PSD “minimización de las consecuencias”, “minimización de la víctima" y "frustración”; con el resto de precipitadores se obtuvieron correlaciones muy bajas.

El análisis de los precipitadores ofrece correlaciones moderadas entre los quince analizados. Así, podemos asumir el principio de independencia entre las variables 
dependientes/independientes, que posibilita poder hacer el análisis de regresión logística posterior.

Revista Española de Investigación Criminológica

Artículo 4, Número 16 (2018)

www.criminologia.net

ISSN: 1696-9219 
Tabla 9.

Correlaciones entre variables dependientes e independientes

\begin{tabular}{|c|c|c|c|c|c|c|c|c|c|c|c|c|c|c|c|c|c|}
\hline & $\mathrm{C} 1$ & $\mathrm{C} 2$ & P1 & $\mathbf{P 2}$ & P3 & P4 & P5 & P6 & P7 & P8 & P9 & P10 & P11 & $\mathbf{P 2}$ & P13 & P14 & P15 \\
\hline C1. CIBERACOSO & 1.000 & $.271^{* *}$ & $.212^{* * *}$ & $.180^{*}$ & 0.084 & 0.052 & $.157^{*}$ & 0.102 & $0 . \overline{-}$ & 0.063 & 0.112 & 0.029 & -0.041 & 0.024 & 0.132 & $.181^{*}$ & 0.062 \\
\hline $\begin{array}{l}\text { C2. } \\
\text { CYBERBULLYING }\end{array}$ & & 1.000 & $.429^{* *}$ & $.509^{* *}$ & $.321^{* *}$ & $.274^{* *}$ & $.279^{* *}$ & $.214^{* *}$ & $.165^{*}$ & $.298^{* *}$ & $.301^{* *}$ & $.209^{* *}$ & 0.110 & 0.144 & -0.085 & $.303^{* *}$ & $.209^{* *}$ \\
\hline P1. Desencadenante & & & 1.000 & $.748^{* *}$ & $.454^{* *}$ & $.299^{* *}$ & $.310^{* *}$ & $.402^{* *}$ & $.370^{* *}$ & $.206^{* *}$ & $.368^{* *}$ & $.262^{* *}$ & $.216^{* *}$ & $.319^{* *}$ & -0.115 & $.255^{* *}$ & $.322^{* *}$ \\
\hline P2. Señales & & & & 1.000 & $.572^{* *}$ & $.452^{* *}$ & $.445^{* *}$ & $.476^{* *}$ & $.349^{* *}$ & $.338^{* *}$ & $.486^{* *}$ & $.433^{* *}$ & $.302^{* *}$ & $.360^{* *}$ & -0.047 & $.348^{* *}$ & $.405^{* *}$ \\
\hline P3. Imitación & & & & & 1.000 & $.537^{* *}$ & $.628^{* *}$ & $.560^{* *}$ & $.370^{* *}$ & $.375^{* *}$ & $.669^{* *}$ & $.454^{* *}$ & $.294^{* *}$ & $.479^{* *}$ & -0.088 & $.350^{* *}$ & $.422^{* *}$ \\
\hline P4. Expectativas & & & & & & 1.000 & $.462^{* *}$ & $.502^{* *}$ & $.427^{* *}$ & $.435^{* *}$ & $.554^{* *}$ & $.532^{* *}$ & $.415^{* *}$ & $.529^{* *}$ & 0.098 & $.298^{* *}$ & $.421^{* *}$ \\
\hline P5. Conformidad & & & & & & & 1.000 & $.525^{* *}$ & $.413^{* *}$ & $.612^{* *}$ & $.483^{* *}$ & $.654^{* *}$ & $.456^{* *}$ & $.474^{* *}$ & -0.094 & $.510^{* *}$ & $.466^{* *}$ \\
\hline P6. Obediencia & & & & & & & & 1.000 & $.511^{* *}$ & $.498^{* *}$ & $.656^{* *}$ & $.446^{* *}$ & $.393^{* *}$ & $.536^{* *}$ & -0.82 & $.525^{* *}$ & $.584^{* *}$ \\
\hline P7. Desafío & & & & & & & & & 1.000 & $.402^{* *}$ & $.652^{* *}$ & $.324^{* *}$ & $.278^{* *}$ & $.339^{* *}$ & -0.061 & $.338^{* *}$ & $.336^{* *}$ \\
\hline P8. Anonimato & & & & & & & & & & 1.000 & $.444^{* *}$ & $.650^{* *}$ & $.564^{* *}$ & $.521^{* *}$ & -0.088 & $.632^{* *}$ & $.581^{* * *}$ \\
\hline P9. Minimizar regla & & & & & & & & & & & 1.000 & $.413^{* *}$ & $.211^{* *}$ & $.432^{* *}$ & -0.088 & $.422^{* *}$ & $.427^{* *}$ \\
\hline $\begin{array}{l}\text { P10. Minimizar } \\
\text { responsabilidad }\end{array}$ & & & & & & & & & & & & 1.000 & $.568^{* *}$ & $.682^{* *}$ & -0.115 & $.487^{* *}$ & $.564^{* *}$ \\
\hline $\begin{array}{l}\text { P11. Minimizar } \\
\text { consecuencias }\end{array}$ & & & & & & & & & & & & & 1.000 & $.751^{* * *}$ & -0.089 & $.491^{* *}$ & $.525^{* *}$ \\
\hline $\begin{array}{l}\text { P12. Minimizar a la } \\
\text { víctima }\end{array}$ & & & & & & & & & & & & & & 1.000 & -0.099 & $.531^{* *}$ & $.691^{* *}$ \\
\hline
\end{tabular}

Revista Española de Investigación Criminológica

Artículo 4, Número 16 (2018)

Www.criminologia.net

ISSN: 1696-9219 
González \& Campoy

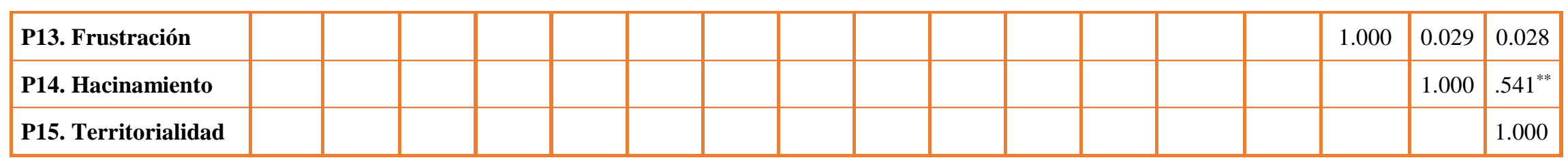




\subsubsection{Modelo de factores de riesgo para el ciberacoso genérico}

El primer modelo generado es para el ciberacoso genérico. Las cuatro variables que forman parte de la ecuación son: "desencadenantes", “imitación”, “minimización las consecuencias" y "hacinamiento". La que mayor poder predictor ofrece es el hacinamiento (26 puntos de mayor probabilidad para el grupo de agresores), seguido de la respuesta a una agresión (desencadenante), con una probabilidad de 2.8 puntos mayor los agresores (Tabla $10)$.

En este modelo el ajuste de los datos es óptimo (prueba de Hosmer y Lemeshow > 0.05). El modelo, con las cuatro variables, es capaz de explicar un $21 \%$ de la variabilidad.

\section{Tabla 10.}

Modelo de análisis de regresión: ciberacoso general

\begin{tabular}{|c|c|c|c|c|c|c|c|}
\hline \multirow{2}{*}{$\begin{array}{l}\text { VARIABLE DEPENDIENTE } \\
\text { Ciberacoso general }\end{array}$} & \multirow[t]{2}{*}{ B } & \multirow[t]{2}{*}{ E.T. } & \multirow[t]{2}{*}{ Wald } & \multirow[t]{2}{*}{ Sig. } & \multirow[t]{2}{*}{$\operatorname{Exp}(B)$} & \multicolumn{2}{|c|}{$\begin{array}{l}\text { I.C. } 95 \% \text { para } \\
\operatorname{EXP}(B)\end{array}$} \\
\hline & & & & & & Inf. & Sup. \\
\hline $\begin{array}{l}\text { Desencadenantes (Respondo a } \\
\text { una agresión rápidamente) }\end{array}$ & 1.024 & 0.340 & 9.068 & $0.003 * *$ & 2.785 & 1.430 & 5.423 \\
\hline $\begin{array}{l}\text { Imitación (Mi familia o amigos } \\
\text { también lo hacen) }\end{array}$ & -3.463 & 1.375 & 6.343 & $0.012 *$ & 0.031 & 0.002 & 0.464 \\
\hline $\begin{array}{l}\text { Minimizar las consecuencias } \\
\text { (No me pasará nada aunque me } \\
\text { pillen) }\end{array}$ & -0.996 & 0.466 & 4.569 & $0.033 *$ & 0.369 & 0.148 & 0.921 \\
\hline $\begin{array}{l}\text { Hacinamiento (Estoy rodeado de } \\
\text { muchas personas) }\end{array}$ & 3.293 & 1.389 & 5.623 & $0.018 *$ & 26.923 & 1.771 & 409.398 \\
\hline Constante & -0.426 & 0.500 & 0.726 & 0.394 & 0.653 & & \\
\hline$-2 \log$ verosimilitud & 195.367 & & & & & & \\
\hline $\mathrm{R}^{2}$ Nagelkerke & .21 & & & & & & \\
\hline $\begin{array}{r}\text { Prueba de Hosmer y Lemeshow } \\
\text { (p) }\end{array}$ & .646 & & & & & & \\
\hline
\end{tabular}

$* * \mathrm{p}<.01 / * \mathrm{p}<.05$ 
Para tratar de afinar un poco más acerca del poder predictor de los precipitadores se obtuvo la curva COR; "desencadenantes" y "hacinamiento" son las dos variables por encima del punto de corte (con un área bajo la curva de 0,6 en el caso de los desencadenantes y de 0,56 en el hacinamiento) (Figura 1, Tabla 11). En este caso la variable que mejor clasifica los valores verdaderos positivos (sensibilidad) del modelo son los desencadenantes, seguido del hacinamiento. Por el contrario, la imitación y minimización de las consecuencias clasifican mayor número de falsos positivos (especificidad), con lo que no son buenas variables predictoras según esta segunda prueba de contraste.

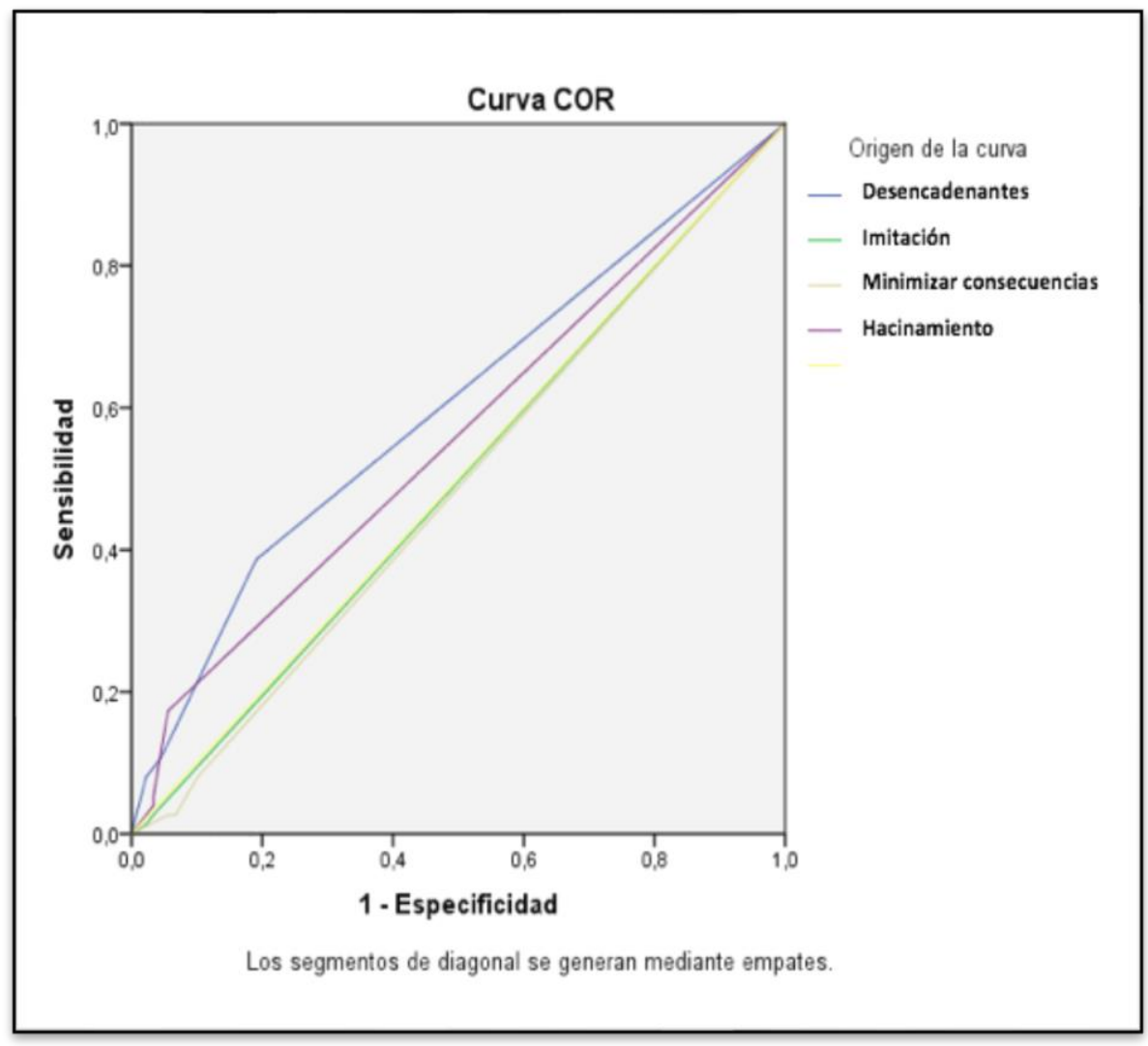

Figura 1. Curva COR, ciberacoso general 


\section{Tabla 11.}

Área bajo la curva ROC, ciberacoso genérico

\begin{tabular}{|c|c|c|c|c|c|}
\hline \multirow{2}{*}{$\begin{array}{c}\text { Variables de resultado } \\
\text { de prueba }\end{array}$} & Área & $\begin{array}{c}\text { Error } \\
\text { estándar }\end{array}$ & \multirow{2}{*}{$\begin{array}{c}\text { Significación } \\
\text { asintótica (b) }\end{array}$} & \multicolumn{2}{|c|}{$\begin{array}{c}\text { 95\% de intervalo de } \\
\text { confianza asintótico }\end{array}$} \\
\cline { 4 - 6 } & & & & $\begin{array}{c}\text { Lím. } \\
\text { inferior }\end{array}$ & $\begin{array}{c}\text { Lím. } \\
\text { superior }\end{array}$ \\
\hline Desencadenantes & .600 & .045 & .028 & .512 & .688 \\
\hline Imitación & .496 & .045 & .937 & .408 & .585 \\
\hline $\begin{array}{c}\text { Minimizar } \\
\text { consecuencias }\end{array}$ & .488 & .045 & .796 & .399 & .577 \\
\hline Hacinamiento & .557 & .045 & .210 & .468 & .646 \\
\hline
\end{tabular}

\subsubsection{Modelo de factores de riesgo para el cyberbullying}

El modelo para el cyberbullying incluye las siguientes variables: "desencadenantes", "señales", "imitación” y "anonimato". La que presenta mayor poder predictivo es el anonimato (4.3 veces más probable para el grupo de los agresores), seguida de las señales (con una probabilidad 3 veces mayor para el grupo de agresores) y los desencadenantes (con 2.7 veces de mayor probabilidad para el grupo de agresores). La imitación ofrece un resultado negativo, esto es, apenas tiene poder predictivo (Tabla 12).

En este segundo modelo los datos ajustan de una manera óptima (prueba de Hosmer y Lemeshow > 0.05), siendo capaz de explicar un $39 \%$ de la variabilidad.

\section{Tabla 12.}

Modelo de análisis de regresión, cyberbullying

\begin{tabular}{|l|c|c|c|c|c|c|c|}
\hline $\begin{array}{l}\text { Variable Dependiente } \\
\text { Cyberbullying }\end{array}$ & B & E.T. & Wald & Sig. & Exp(B) & \multicolumn{2}{|c|}{\begin{tabular}{c} 
EXP(B) \\
\cline { 5 - 8 }
\end{tabular}} \\
\hline $\begin{array}{l}\text { Desencadenantes } \\
\text { (Respondo a una agresión } \\
\text { rápidamente) }\end{array}$ & 0.985 & 0.459 & 4.616 & $0.032 *$ & 2.678 & 1.090 & 6.578 \\
\hline $\begin{array}{l}\text { Señales (La otra persona lo } \\
\text { merece) }\end{array}$ & 1.085 & 0.379 & 8.180 & $0.004 * *$ & 2.959 & 1.407 & 6.222 \\
\hline
\end{tabular}




\begin{tabular}{|r|c|c|c|c|c|c|c|}
\hline $\begin{array}{l}\text { Imitación (Mis amigos lo } \\
\text { hacen y es lo que hay que } \\
\text { hacer) }\end{array}$ & -2.595 & 0.816 & 10.117 & $0.001 * *$ & 0.075 & 0.015 & 0.369 \\
\hline $\begin{array}{l}\text { Anonimato (Es muy raro } \\
\text { que me pillen) }\end{array}$ & 1.465 & 0.622 & 5.550 & $0.018^{*}$ & 4.326 & 1.279 & 14.632 \\
\hline Constante & -2.561 & 0.601 & 18.128 & 0.000 & 0.077 & & \\
\hline$-2 \log$ verosimilitud & 153.003 & & & & & & \\
\hline $\mathrm{R}^{2}$ Nagelkerke & .39 & & & & & & \\
\hline $\begin{array}{l}\text { Prueba de Hosmer y } \\
\text { Lemeshow (p) }\end{array}$ & .137 & & & & & & \\
\hline
\end{tabular}

$* * \mathrm{p}<.01 / * \mathrm{p}<.05$

El análisis de la curva COR indica que las cuatro variables muestran un área bajo la curva superior a 0.5, siendo las señales la que mayor área ocupa (0.75), seguida de los desencadenantes (0.7) y por último el anonimato y la imitación (Figura 2 y Tabla 13). Aquí se puede observar que las cuatro variables son capaces de identificar mayor número de verdaderos positivos (sensibilidad) que falsos positivos (especificidad); además, las señales y los desencadenantes obtienen una puntuación muy elevada, por encima de 0.7.

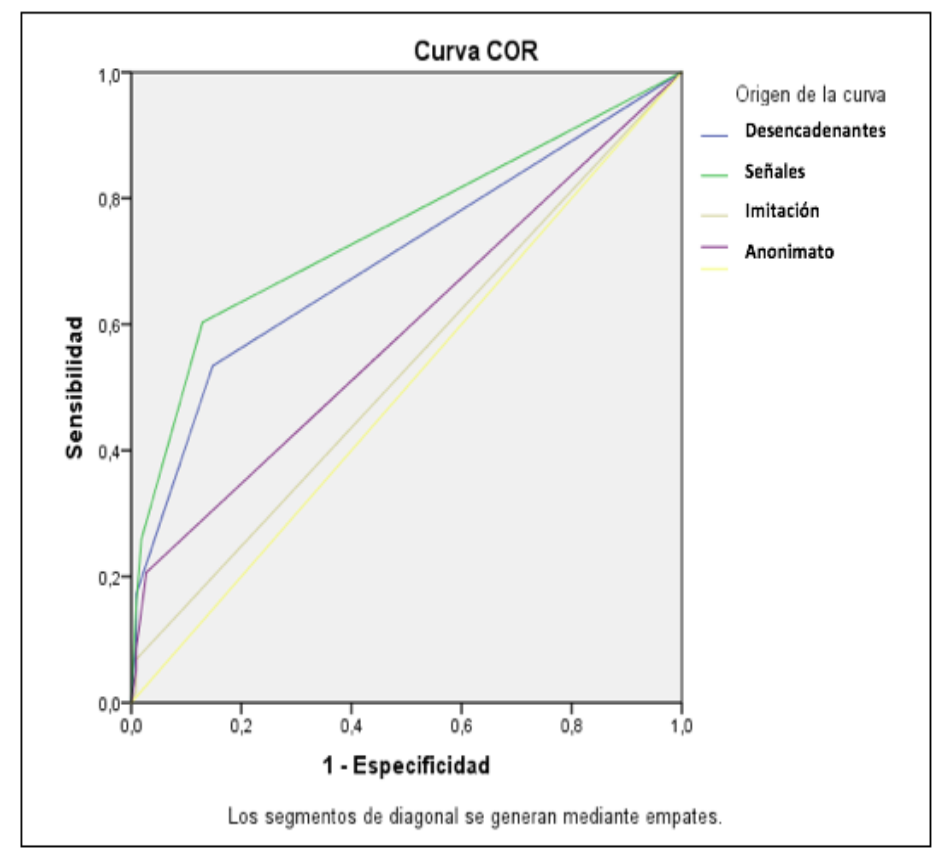

Figura 2. Curva COR, cyberbullying

Revista Española de Investigación Criminológica

Artículo 4, Número 16 (2018)

Www.criminologia.net

ISSN: 1696-9219 


\section{Tabla 13.}

Área bajo la curva COR, cyberbullying

\begin{tabular}{|c|c|c|c|c|c|}
\hline \multirow{2}{*}{$\begin{array}{c}\text { Variables de resultado } \\
\text { de prueba }\end{array}$} & Área & $\begin{array}{c}\text { Error } \\
\text { estándar }\end{array}$ & $\begin{array}{c}\text { Significación } \\
\text { asintótica (b) }\end{array}$ & \multicolumn{2}{|c|}{$\begin{array}{c}\text { 95\% de intervalo de } \\
\text { confianza asintótico }\end{array}$} \\
\cline { 5 - 6 } & & & $\begin{array}{c}\text { Límite } \\
\text { inferior }\end{array}$ & $\begin{array}{c}\text { Límite } \\
\text { superior }\end{array}$ \\
\hline Desencadenantes & .703 & .045 & .000 & .614 & .792 \\
\hline Señales & .748 & .043 & .000 & .663 & .833 \\
\hline Imitación & .530 & .048 & .530 & .436 & .623 \\
\hline Anonimato & .590 & .048 & .057 & .495 & .684 \\
\hline
\end{tabular}

\section{Conclusiones y discusión}

En relación con el objetivo principal del estudio, y para tratar de validar o refutar nuestra primera hipótesis, en cuanto al poder explicativo de los PSD, los resultados parecen confirmarla, dado que en el caso del cyberbullying se explica hasta un 39\% de la variabilidad de la conducta, y un $21 \%$ para el caso del ciberacoso genérico.

Con respecto a la segunda hipótesis, relacionada con el poder predictivo y la frecuencia de aparición de los PSD en las conductas de ciberacoso, los resultados también parecen confirmarla, pero de manera parcial, porque el precipitador más frecuente es el de las señales aunque sólo para el caso del cyberbullying. El siguiente precipitador más frecuente es el desencadenante, y este sí es un factor predictor en ambas conductas.

Nuestra tercera hipótesis, aquella relacionada con la diferenciación de los PSD en las conductas de ciberacoso genérico y específico, también parece confirmarse. A pesar de que los desencadenantes se encuentran en los dos modelos predictivos, el resto de precipitadores no; el hacinamiento sólo es predictor del ciberacoso genérico y el anonimato y las señales únicamente del cyberbullying.

Así mismo, los resultados indican que es conveniente utilizar una definición diferenciada de ciberacoso (general) y cyberbullying, pudiendo esta última conducta ser una categoría de la primera, como conclusión extraída del objetivo secundario de este trabajo. Un indicador de este hecho es que la conducta de ciberacoso genérico es más frecuente (43.2\%) que la de cyberbullying (26.7\%). Otro aspecto que apoyaría la necesidad de diferenciar los

\section{Revista Española de Investigación Criminológica}


conceptos es que las conductas más frecuentes para el primer caso son la difusión de rumores o cotilleos y el reenvío de los enlaces con estos comentarios, y para el segundo caso del cyberbullying la forma más frecuente es el envío de comentarios e imágenes injuriosas. Por este motivo se puede concluir que las dos conductas objeto de examen tendrían una naturaleza diferente: en el ciberacoso no se utilizan imágenes, mientras que en el cyberbullying sí, y se vierten comentarios que van más allá de los simples rumores, aumentándose el daño. Además, el hecho de que exista una configuración distinta de los precipitadores en las conductas también indicaría que son dos constructos diferenciados, siendo además las correlaciones entre ambos muy bajas.

Así, del análisis de los PSD se desprenden algunas reflexiones para la discusión, como el hecho de que las razones esgrimidas por los agresores son distintas en función de la conducta. Para el ciberacoso genérico, el hecho de estar rodeado de muchos usuarios en el entorno virtual puede indicar que el individuo siente cierta presión a la hora de que la conducta realizada tenga un impacto mayor entre la comunidad de usuarios. También los desencadenantes pueden indicar que el mantenimiento de cierto estatus dentro de la comunidad afecta al proceso de toma de decisiones. Pero en este caso no podemos poner en relación estos hallazgos con investigaciones previas porque no se han encontrado, más allá de aquellas expuestas para el cyberbullying (ciberacoso específico).

No obstante, en la conducta de cyberbullying cobra relevancia el anonimato, junto con las señales y la minimización de la víctima. Esto parece indicar que el sistema de relaciones de origen (la relación entre iguales en la escuela) es importante a la hora de cometer estas conductas, intentando el sujeto no ser detectado por la víctima y percibiendo que, por un lado, el comportamiento es esperado en el entorno en el que se desarrolla y, por otro, que la víctima merece ser acosada. En el caso de las señales, los resultados son coherentes con los estudios previos que han identificado este tipo de ciberacoso como conducta reactiva, en lugar de proactiva (Ang, Huan, \& Florell, 2013; Barlett et al., 2013; Zhou et al., 2013).

La aparición de estas diferencias en el proceso de toma de decisiones de los agresores podría ayudar a generar estrategias preventivas diferenciadas según las conductas a evitar. Pese a darse en el mismo "lugar" (el ciberespacio), y ser de naturaleza similar, los resultados

\section{Revista Española de Investigación Criminológica}


parecen indicar que ambas conductas tienen especificidades que necesitan ser atendidas por futuros trabajos.

En relación a las limitaciones, una de las primeras es el tamaño muestral, dada la proporción del grupo de agresores, siendo deseable contar con un mayor número de casos. Además, en este estudio los hallazgos se circunscriben a la población escolar de centros públicos de la zona Noroeste de Madrid, como se ha indicado en la metodología.

Otra limitación se refiere a la operativización de los PSD. El método utilizado (narrativas dirigidas) se ha empleado en trabajos relacionados con la teoría del rol (Hubbert, García-Sehorn, \& Brown, 1995), puesto que, como Schank y Abelson (1977; Abelson, 1981) han señalado, este tipo de "scripts" situacionales se dan dentro de un contexto determinado, en el que los participantes interactúan y comparten significados sobre lo que debe suceder. En este sentido, es complicado diferenciar el esquema cognitivo seguido por el individuo (Borrion, 2013) de la motivación que impele el comportamiento. Aunque los scripts son definidos como "estructuras cognitivas que organizan las secuencias de los eventos en un contexto determinado de forma estereotipada" (Schank \& Abelson, 1977, pp.41) y permiten de "manera sencilla... resumir los aspectos procedimentales del delito" (Cornish, 1994, pp.175), orientar las respuestas de los participantes no permite conocer en profundidad el contexto en el que surge la conducta. No obstante, el potencial uso de esta perspectiva desde la prevención tiene que ver con el hecho de que la conducta puede cambiar si existen factores inhibitorios en ese contexto (Tedeschi \& Felson, 1994). Pero es posible hallar estudios en los que se han introducido narrativas dirigidas, como el de Grasmick y Bursik (1990), quienes interpretaron las respuestas como indicadores de comportamiento (Lyn-Exum \& Bouffard, 2010). Las críticas principales van en la línea de lo expuesto: las preguntas no consideraban el contexto en el cual se desarrollan las acciones (Klepper \& Nagin, 1989).

Como corolario, en el futuro sería aconsejable que en el ámbito del análisis criminológico se consensuasen definiciones, indicadores y metodologías, dado que como señalan Hamby y Finkelhor (2000) estas cuestiones afectan a la validez y a la replicabilidad de los estudios. 


\section{Referencias}

Abelson, R. P. (1981). Psychological status of the script concept. American Psychologist, 36(7), 715-729. DOI: 10.1037/0003-066X.36.7.715

Agnew, R. (1992). Foundation for a general strain theory of crime and delinquency. Criminology, 30(1), 47-88. DOI: 10.1111/j.1745-9125.1992.tb01093.x

Agustina, J. R., \& Felson, M. (2016). Routine Activities, Delinquency, and Youth Convergences. En A. R. Piquero (Ed.), The Handbook of Criminological Theory (pp.136-155). Chichester: Wiley Blackwell. DOI: 10.1002/9781118512449.ch8

Ajzen, A. (2012). The theory of planned behavior. En P. Van Langre, A. Kruglanski, \& E. Higgins (Eds.), Handbook of theories of social psychology (pp.438-459). Londres: Sage. DOI: 10.4135/9781446249215.n22

Akbulut, Y., Şendağ, S., Birinci, G., Kiliçer, K., Mehmet, C. S., \& Odabaşi, H. F. (2008). Exploring the types and reasons of Internet-triggered academic dishonesty among Turkish undergraduate students: Development of Internet-Triggered Academic Dishonesty Scale (ITADS). Computers and Education, 51(1), 463-4730. DOI: 10.1016/j.compedu.2007.06.003

Ang, R. P, Huan, V. S., \& Florell, D. (2013). Understanding the Relationship Between Proactive and Reactive Aggression, and Cyberbullying Across United States and Singapore Adolescent Samples. Journal of Interpersonal Violence, 29(2), 237-254. DOI: $10.1177 / 0886260513505149$

Avilés, J. (2009). Cyberbullying. Diferencias entre el alumnado de secundaria. Boletín de Psicología, 96, 79-96.

Baggili, I., \& Rogers, M. (2009). Self-Reported Cyber Crime: An Analysis on the Effects of Anonymity and Pre-Employment Integrity. International Journal of Cyber Criminology, 3(2), 550-565.

Bandura, A. (1999). A social cognitive theory of personality. En L. Pervin, \& O. John (Eds.), Handbook of personality (2nd ed., pp.154-196). Nueva York: Guilford Publications.

Bandura, A., Ross, D., \& Ross, S. A. (1963). Imitation of film-mediated aggressive models. The Journal of Abnormal and Social Psychology, 66(1), 3-11. DOI: $10.1037 / \mathrm{h} 0048687$

Barlett, C. P., Gentile, D. A., Anderson, C. A., Suzuki, K., Sakamoto, A., Yamaoka, A., \& Katsura, R. (2013). Cross-Cultural Differences in Cyberbullying Behavior. A ShortTerm Longitudinal Study. Journal of Cross-Cultural Psychology, 45(2), 300-313. DOI: $10.1177 / 0022022113504622$

Bartrina, M. J. (2012). Análisis y abordaje del acoso entre iguales mediante el uso de las nuevas tecnologías. Justicia juvenil y adolescentes en la era digital. Barcelona: Generalitat de Catalunya. Departamento de Justicia. Centro de Estudios Jurídicos y Formación Especializada.

Basamanowicz, J., \& Bouchard, M. (2011). Overcoming the Warez Paradox: Online Piracy Groups and Situational Crime Prevention. Policy \& Internet, 3(2), 1-25. DOI: 10.2202/1944-2866.1125

Borrion, H. (2013). Quality assurance in crime scripting. Crime Science, 2, 1-12. DOI: $10.1186 / 2193-7680-2-6$

Revista Española de Investigación Criminológica

Artículo 4, Número 16 (2018)

www.criminologia.net

ISSN: 1696-9219 
Buelga, S., Cava, M., \& Musitu, G. (2010). Cyberbullying: victimización entre adolescentes a través del teléfono móvil y de Internet. Psicothema, 22(4), 784-789.

Campoy, P., \& Summers, L. (2015). Los precipitadores situacionales del delito: otra mirada a la interacción persona-ambiente. Revista Criminalidad, 57(3), 41-58.

Cockbain, E., \& Wortley, R. (2015). Everyday atrocities: does internal (domestic) sex trafficking of British children satisfy the expectations of opportunity theories of crime? Crime Science, 4, 1-12. DOI: 10.1186/s40163-015-0047-0

Cohen L. E., \& Felson, M. (1979). Social change and crime rate trends: A routine activity approach. American Sociological Review, 44(4), 588-608. DOI: 10.2307/2094589

Cornish, D. B. (1994). The procedural analysis of offending and its relevance for situational prevention. En R. V. Clarke (Ed.), Crime prevention studies (pp.151-196). Monsey: Criminal Justice Press.

Cortina, J. M. (1993). What is coefficient alpha? An examination of theory and applications. Journal of Applied psychology, 78(1), 98-104. DOI: 10.1037/0021-9010.78.1.98

Defensor del Pueblo. (2007). Violencia escolar: el maltrato entre iguales en la Educación Secundaria Obligatoria. 1999-2006. Madrid: Publicaciones de la Oficina del Defensor del Pueblo.

Doane, A. N., Pearson, M. R., \& Kelley, M. L. (2014). Predictors of cyberbullying perpetration among college students: an application of the Theory of Reasoned Action. Computers in Human Behavior, 36, 154-162. DOI: 10.1016/j.chb.2014.03.051

Felson, M. (2015). Lectio Doctoralis. El estudio científico del delito. En F. Miró, J. R. Agustina, J. E. Medina, \& L. Summers (Eds.), Crimen, oportunidad y vida diaria. Libro Homenaje al Profesor Dr. Marcus Felson (pp.23-28). Madrid: Dykinson.

Garaigordobil, M., \& Aliri, J. (2013). Ciberacoso (cyberbullying) en el País Vasco. Diferencias de sexo en víctimas, agresores y observadores. Psicología Conductual, 21(3), 461-474.

González, A. (2015). El cyberbullying o acoso juvenil a través de Internet: un análisis empírico a través del modelo del Triple Riesgo Delictivo (TRD). Tesis doctoral. Departamento de Personalidad, Evaluación y Tratamientos Psicológicos. Barcelona: Universitat de Barcelona.

Gutiérrez- Rubí, A. (2014). 6 rasgos clave de los milennials. Forbes, 22 de diciembre.

Grasmick, H. G., \& Bursik, R. J. (1990). Conscience, Significant Others, and Rational Choice: Extending the Deterrence Model. Law and Society Review, 24(3), 837-861. DOI: $10.2307 / 3053861$

Hamby, S. L., \& Finkelhor, D. (2000). The victimization of children: Recommendations for assessment and instrument development. Journal of the American Academy of Child and Adolescent Psychiatry, 39(7), 829-840. DOI: 10.1097/00004583-20000700000011

Heirman, W., \& Walrave, M. (2012). Predicting adolescent perpetration in cyberbullying: an application of the theory of planned behavior. Psicothema, 24(4), 614-620.

Hinduja, S. (2008). Deindividuation and internet software piracy. Cyberpsychology and Behavior, 11(4), 391-398. DOI: 10.1089/cpb.2007.0048

Revista Española de Investigación Criminológica

Artículo 4, Número 16 (2018)

www.criminologia.net

ISSN: 1696-9219 
Hinduja, S., \& Ingram, J. R. (2008). Self-control and ethical beliefs on the social learning of intellectual property theft. Western Criminology Review, 9(2), 52-72.

Homel, R., MacIntyre, S., \& Wortley, R. (2014). How house burglars decide on targets: a computer-based approach. En B. Leclerc, \& R. Wortley (Eds.), Cognition and crime: Offender decision making and script analyses (pp.26-47). Nueva York: Routledge.

Hubbert, A. R., García-Sehorn, A., \& Brown, S. W. (1995). Service expectations: the consumer versus the provider. International Journal of Service Industry Management, 6(1), 6-21. DOI: 10.1108/09564239510146672

Instituto Nacional de Estadística (2017). Estadísticas del uso de Internet en España. Madrid: Ministerio del Interior.

Instituto Nacional de Tecnologías de la Información (INTECO) (2010). Estudio sobre hábitos seguros en el uso de smartphones por los niños y adolescentes españoles. León: INCIBE.

Jang, H., Song, J., \& Kim, R. (2014). Does the offline bully-victimization influence cyberbullying behavior among youths? Application of General Strain Theory. Computers in Human Behavior, 31, 85-93. DOI: 10.1016/j.chb.2013.10.007

Klepper, S., \& Nagin, D. (1989). The deterrent effect of perceived certainty and severity of punishment revisited. Criminology, 27(4), 721-746. DOI: 10.1111/j.17459125.1989.tb01052.x

Lazuras, L., Barkoukis, V., Ourda, D., \& Tsorbatzoudis, H. (2013). A process model of cyberbullying in adolescence. Computers in human behaviour, 29(3), 881-887. DOI: 10.1016/j.chb.2012.12.015

Maimon, D., Alper, M., Sobesto, B., \& Cukier, M. (2014). Restrictive deterrent effects of a warning banner in an attacked computer system. Criminology, 52(1), 33-59. DOI: 10.1111/1745-9125.12028

Lyn-Exum, M., \& Bouffard, J. A. (2010). Testing Theories of Criminal Decision Making: Some Empirical Questions about Hypothetical Scenarios. En A. R. Piquero, \& D. Weisburd (Eds.), Handbook of Quantitative Criminology (pp.581-594.). Nueva York: Springer. DOI: 10.1007/978-0-387-77650-7_28

Miró, F. (2011). La oportunidad criminal en el ciberespacio. Aplicación y desarrollo de la teoría de las actividades cotidianas para la prevención del cibercrimen. Revista Electrónica de Ciencia Penal y Criminología, 13-07, 1-55.

Miró, F. (2012). El cibercrimen. Fenomenología y criminología de la delincuencia en el ciberespacio. Madrid: Marcial Pons.

Miró, F., \& García, N. (2014). Ciberapp: estudio sobre el alcance de la cibercriminalidad contra menores en la provincia de Alicante. Alicante: Diputación de Alicante.

Mora-Merchán, J., Ortega, R., Calmaestra, J., \& Smith, P. (2010). El uso violento de la tecnología: el cyberbullying. En R. Ortega, (Ed.), Agresividad Injustificada, bullying y violencia escolar (pp.189-209). Madrid: Alianza.

Observatorio Estatal de Convivencia Escolar (2008). Estudio estatal sobre la convivencia escolar en la educación secundaria obligatoria. Madrid: Ministerio de Sanidad.

Olweus, D. (1993). Bullying at school. What we know and what we can do. Oxford: Blackwell. 
Pardo-Merino, A., \& Ruiz-Díaz, M. (2002). SPSS 11: Guía para el análisis de datos. Madrid: McGraw-Hill.

Patchin, J. W., \& Hinduja, S. (2006). Bullies move beyond the schoolyard: a preliminary look at cyberbullying. Youth violence and Juvenile Justice, 4(2), 148-169. DOI: $10.1177 / 1541204006286288$

Patchin, J. W., \& Hinduja, S. (2011). Traditional and nontraditional bullying among youth: A test of general strain theory. Youth \& Society, 43(2), 727-751. DOI: $10.1177 / 0044118 X 10366951$

Patchin, J. W., \& Hinduja, S. (2012). Cyberbullying. An update and synthesis of the research. En J. W. Patchin, \& S. Hinduja (Eds.), Cyberbullying prevention and response. Expert perspectives (pp.13-36). Nueva York: Routledge.

Pornari, C. D., \& Wood, J. (2010). Peer and cyber aggression in secondary school students: The role of moral disengagement, hostile attribution bias, and outcome expectancies. Aggressive Behavior, 36(2), 81-94. DOI: 10.1002/ab.20336

Reyns, B. W. (2010). A situational crime prevention approach to cyberstalking victimization: Preventive tactics for Internet users and online place managers. Crime Prevention and Community Safety, 12(2), 99-118. DOI: 10.1057/cpcs.2009.22

Romera, E. M., Cano, J. J., García-Fernández, C. M., \& Ortega, R. (2016). Cyberbullying: competencia social, motivación y relaciones entre iguales. Comunicar, 48(24), 71 79. DOI: $10.3916 / \mathrm{C} 48-2016-07$

Ševčíková, A., \& Šmahel, D. (2009). Online Harassment and Cyberbullying in the Czech Republic Comparison Across Age Groups. Journal of Psychology, 217(4), 227-229. DOI: $10.1027 / 0044-3409.217 .4 .227$

Schank, R. C., \& Abelson, R. P. (1977). Scripts, Plans, Goals and Understanding. Nueva York: Wiley.

Sticca, F., Ruggieri, S., Alsaker, F., \& Perren, S. (2013). Longitudinal Risk Factors for Cyberbullying in Adolescence. Journal of Community and Applied Social Psychology, 23(1), 52-67. DOI: 10.1002/casp.2136

Stockman, M. (2014). Insider hacking: applying situational crime prevention to a new whitecollar crime. Proceedings of the 3rd annual conference on Research in information technology (pp. 53-56). Nueva York: ACM. DOI: 10.1145/2656434.2656436

Tedeschi, J., \& Felson, R. B. (1994). Violence, aggression, and coercive actions. Washington: American Psychological Association. DOI: 10.1037/10160-000

Thompson, C. M., \& Leclerc, B. (2014). The rational choice perspective and the phenomenon of stalking: an examination of sex differences in behaviours, rationales, situational precipitators and feelings. En B. Leclerc, \& R. Wortley (Eds.), Cognition and crime: Offender decision making and script analyses (pp.70-100). Nueva York: Routledge.

UNESCO (2016). Ending the torment: tackling bullying from the schoolyard to cyberspace. Nueva York: United Nations Publications.

Wortley, R. (1998). A two-stage model of situational crime prevention. Studies on Crime and Crime Prevention, 7, 173-188

Wortley, R. (2008). Situational precipitators of crime. En R. Wortley, \& L. Mazerolle (Eds.), Environmental criminology and crime analysis (pp.48-69). Cullompton: Willan.

Revista Española de Investigación Criminológica

Artículo 4, Número 16 (2018)

https://doi.org/10.46381/reic.v16i0.149

Www.criminologia.net

ISSN: 1696-9219 
Zhou, Z., Tang, H., Tian, Y., Wei, H., Zhang, F., \& Morrison, C. M. (2013). Cyberbullying and its risk factors among Chinese high school students. School Psychology International, 34(6), 630-647. DOI: 10.1177/0143034313479692

Abel González García es Doctor en Criminología por la Universidad de Barcelona. Director del Departamento de Criminología de la Universidad a Distancia de Madrid (UDIMA). Investigador asociado del Centro Crímina de la Universidad Miguel Hernández de Elche. Sus líneas de investigación actuales son: bullying-cyberbullying; cibercriminología, evidence based policing, media criminology.

iD https://orcid.org/0000-0001-6808-1503

Pedro Campoy Torrente es doctorando de la Universidad de Málaga. Profesor Asociado de la Universidad Rey Juan Carlos. Director de 4C Consultores. Sus líneas actuales de investigación son: bullying/cyberbullying, análisis de la toma de decisiones y precipitadores del delito, criminología ambiental.

iD https://orcid.org/0000-0001-9237-0719 